\title{
Optical and Structural Study of ZnO Thin Films Deposited by RF Magnetron Sputtering at Different Thicknesses: a Comparison with Single Crystal
}

\author{
Abdul Kader Jazmatia , Bassam Abdallah ${ }^{a}{ }^{(1)}$ \\ ${ }^{a}$ Department of Physics, Atomic Energy Commission of Syria, P. O. Box 6091, Damascus, Syria
}

Received: September 11, 2017; Revised: January 23, 2018; Accepted: February 25, 2018

\begin{abstract}
Optical characterizations of preferred orientation (002) $\mathrm{ZnO}$ thin films, prepared by $\mathrm{RF}$ magnetron sputtering under pure argon plasma, with different thicknesses have been investigated, where grain size and resistivity increase with thickness. Energy band gap and refractive indices have been calculated. A correlation between band gap values and crystalline quality, which is improved with thickness, has been discussed. The calculated refractive indices of the thicker deposited films have increased as the thickness increases. Full width Half Maxima (FWHM) of band gap Photoluminescence (PL) emission decreases with thickness increasement due to quality improvement as it has been monitored by X-Ray Diffraction (XRD). A comparison between PL spectra of $1200 \mathrm{~nm}$ film and $\mathrm{ZnO}$ single crystal at low temperature is found to be similar.
\end{abstract}

Keywords: Thin films, Zinc oxide, structure properties, Photoluminescence, UV characteristics.

\section{Introduction}

Due to the interesting properties of $\mathrm{ZnO}$ composite such as its high abundance in nature, stability, nontoxicity, high transparency and wide band gap (about $3.3 \mathrm{eV}$ ), it is widely used as a semiconductor. It is a principle layer in a solar cells $^{1,2}$, liquid crystal display (LCD), light emitting diode (LED) and as a thin film transistor (TFT) ${ }^{3-6}$. It is also used as surge protection devices ${ }^{7-9}, \mathrm{UV}$ photodetector, transparent conductor, surface acoustic wave device and gas sensor ${ }^{10-13}$.

AZO thin films have been prepared by different synthesis methods ${ }^{14-16}$, where high quality $\mathrm{ZnO}$ films can be produced with a controlled thickness by using DC or RF magnetron sputtering in the semiconductor technology manufacturing ${ }^{17}$.

For instance, Suvorova et al. ${ }^{18}$ have grown an epitaxial $\mathrm{ZnO}$ films by $\mathrm{RF}$ magnetron sputtering at room temperature followed by rapid thermal annealing. But Rahmane et al. ${ }^{17}$ managed to obtain an epitaxial growth of $\mathrm{ZnO}$ thin films at low temperature by choosing an appropriate substrate (good quality AIN) RF sputtering.

Park et al. ${ }^{19}$ have studied PL emissions for $\mathrm{ZnO}$ single crystal nanorods at low temperature raging from $10 \mathrm{~K}$ to RT and found that the intensity of bound exciton peaks are increased with decreasing temperature on contrary to free exciton peak where it decreases.

In Previous work, it has been demonstrated that the increased substrate temperature accompanied with improvement of $\mathrm{ZnO}$ film quality where the band gap extracted by UV transmittance spectrum was about $3.2 \mathrm{eV}$ at $400{ }^{\circ} \mathrm{C}$. The electrical characteristics via $\mathrm{C}-\mathrm{V}$ and $\mathrm{I}-\mathrm{V}$ measurements on the basis of the heterojunction thermal emission model confirm the domination of high-density grain boundary layer existing at the interface ${ }^{20}$.

Therefore, in order to investigate the effect of thickness on the structural and optical properties of $\mathrm{ZnO}$ films, we have grown a set of films on $\mathrm{Si}$ and glass substrates where XRD technique was employed to explore the structural modification improvements due to increasing the thickness and EDX analysis method was utilized to reveal information about the composition of the films. PL and UV techniques were provided to monitor the optical band gap where a slight increasement is found with varied thickness. PL spectra at low temperature (LT) for $\mathrm{ZnO}$ thick film and single crystal have been compared.

\section{Experimental Details}

PLASSYS-MP600S deposition system was used to elaborate Zinc oxide films using RF magnetron sputtering. $\mathrm{Si}(100)$ and glass substrates were used to prepare the films. The purity and the diameter of the zinc oxide target were $99.99 \%$ and $15 \mathrm{~cm}$ respectively. The deposition rate $(1.23 \mathrm{~nm} / \mathrm{s})$ at RF power $600 \mathrm{~W}$ and morphology were obtained from a scanning electron microscope (SEM) TSCAN Vega II XMU (Czech Republic) operated at $30 \mathrm{kV}$. The Energy Dispersive $\mathrm{X}$-ray Spectroscopy (EDX) is used to determine the atomic composition of the $\mathrm{ZnO}$ films. The thickness varied from 10 $\mathrm{nm}$ to $1200 \mathrm{~nm}$. All the deposition conditions are summarized in a previous work ${ }^{21}$. 
The crystallographic properties of the films have been analysed by X-ray Diffraction (XRD) Stoe Stadi P Transmission X-ray diffractometer (Germany) using the $\mathrm{Cu} \mathrm{K \alpha}$ (with $\lambda=0.15405 \mathrm{~nm}$ ) radiation in a linear position sensitive detector for $\theta-2 \theta$ scan configuration. The optical characteristics have been examined using the UV-vis Shimadzu UV-310PC Spectrophotometer to measure the transmittance of the elaborated films, and a $325 \mathrm{~nm}$ wavelength of a He-Cd laser, a $1 \mathrm{~m}$ Spex monochromator and a multialkali photomultiplier were used for the photoluminescence (PL) measurements at RT as well as LT.

\section{Results and Discussion}

\subsection{Structural study}

Figure 1(a) shows the XRD patterns for $\mathrm{ZnO}$ films with different thicknesses raging from $1200 \mathrm{~nm}$ down to $50 \mathrm{~nm}$. A (002) preferential orientation peak at $34.42^{\circ}$ is found, which could be assigned to the hexagonal $\mathrm{ZnO}$ würtzite phase with the c-axis perpendicular to the substrate surface, and small (100) peak at $31.4^{\circ}$. The stoichiometry $(\mathrm{O} / \mathrm{Zn}$ about 1$)$ was verified by EDX analysis.

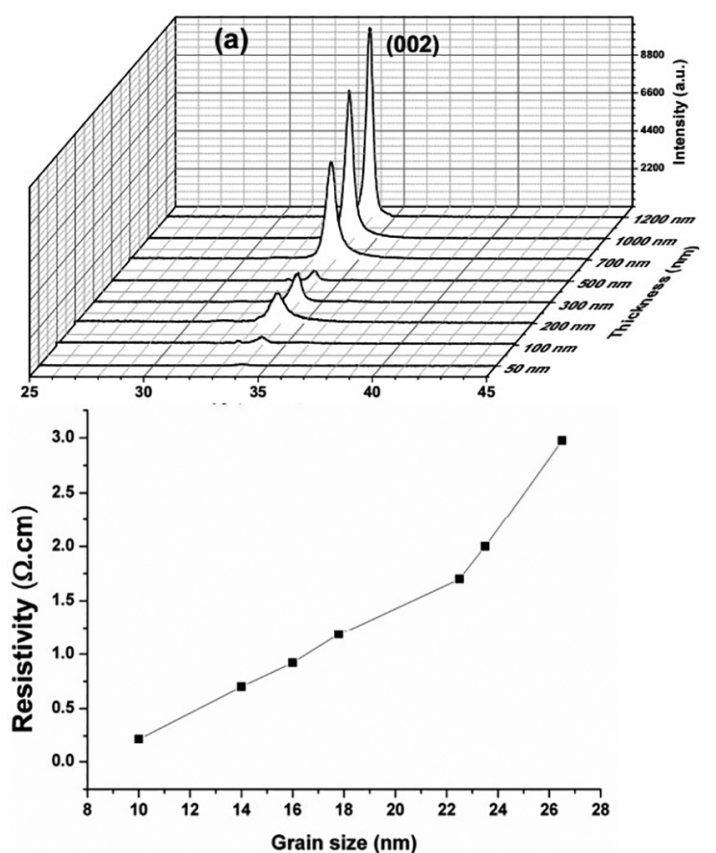

Figure 1. (a) XRD patterns, (b) Resistivity as a function of grain size of (002) peaks for $\mathrm{ZnO}$ films with different thickness.

Grain size has been deduced from XRD pattern using Scherrer's formula for (002) peaks of $\mathrm{ZnO}$ films and it was found to increase from $10 \mathrm{~nm}$ to $27 \mathrm{~nm}$ with increasing the thickness. Rocking curve results showed an improvement of the films crystallinity, whereas the FWHM decreases from $16^{\circ}$ to $2.9^{\circ}$ for films at 50 and $1200 \mathrm{~nm}$, respectively. The residual stress is a compressive stress that decreases with increasing thickness ${ }^{21}$.

Van der Pauw technique ${ }^{22}$ has been used to estimate the room temperature resistivity $\rho$ of the films where it increases with thickness as shown in figure 1(b). The conductivity of the films gets lower as the thickness increases due to reduction in the carrier concentration, which is inversely proportional to the resistivity, where it decreases from 2.975 to $0.2184 \Omega$ $\mathrm{cm}$ for 1200 down to $30 \mathrm{~nm}$ thickness respectively ${ }^{21}$. This manner is also noticed by Myoung et al. ${ }^{23}$. This means that the thicker films have less defects concentrations (bigger grain size and fine grain boundary). The behavior of increasing the resistivity with average grain size, as shown in figure 1(b), comes in consistent with other work ${ }^{24}$.

\subsection{Optical properties}

\subsubsection{UV study}

Figure 2(a) shows the UV transmissions spectra for thinner films (10-200 nm) and figure 2(b) for higher thickness (500 -1200 nm). It has been observed that the average transmittance of samples in the visible range rises from 83 $\%$ to $95 \%$ as shown in the spectra of $\mathrm{ZnO}$ films. The optical transmittance provides useful information about the optical band gap of the semiconductor ${ }^{20}$ where it extend the linear part of $\alpha^{2}$ as a straight asymptotic line that intercepts the horizontal axis $\alpha^{2}=0$ yielding $\mathrm{Eg}$ from $\mathrm{h} v$ value as shown in figure 2(c) and (d).

The obtained values of band gap for different thicknesses are summarized in table 1 where, in general behavior, there is a value increasement with the thickness increase accompanied by an improvement of the crystalline quality, where it is attributed to the strain in the film introduced during the deposition ${ }^{21}$, i.e. the thicker films suffer less strain than thinner ones and consequently higher band gab values. This comes in a good agreement with our results where thicker films have lower stress value and better quality.

The obtained values of energy gap show that the sample thickness influences to some extent the gap. However, this influence is not sufficiently important.

Figure 3 shows the evolution of the refractive index (n) as a function of wavelength for different thicknesses of the films raging from (500 - $1200 \mathrm{~nm})$. The optical constant (Refractive index $\mathrm{n}$ ) of $\mathrm{ZnO}$ films on glass substrate were calculated from transmittance measurement by using Manifacier's envelop method ${ }^{25}$. The variation of optical constant (n) with wavelength $(\lambda)$ shows a decrease with increasing wavelength $(\lambda)$ due to decreased absorption of traps and intraband transitions ${ }^{26}$. These results are in conformity with the results ${ }^{27}$.

According to an investigation by Moustaghfir et al. ${ }^{28}$, the refractive index ( $n$ at $\lambda=633 \mathrm{~nm}$ ) of the radio frequency (RF.) magnetron reactive sputtered $\mathrm{ZnO}$ film (a thickness of $\sim 800 \mathrm{~nm}$ ) fabricated under the sputtering was 1.89 and 

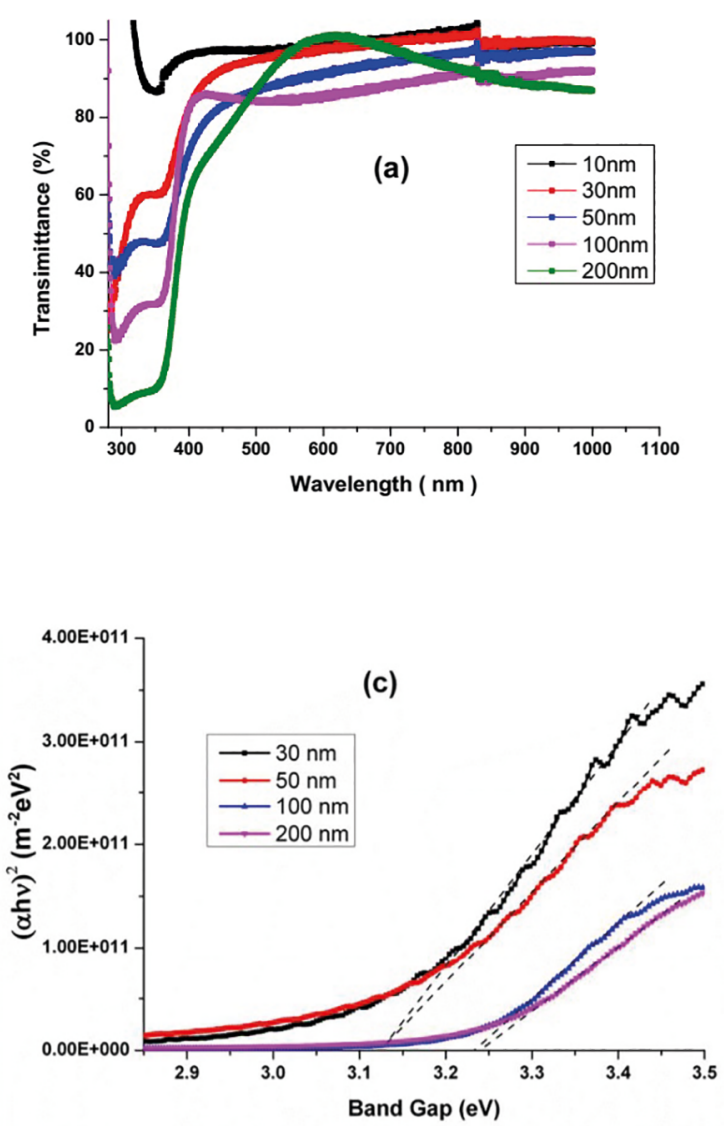
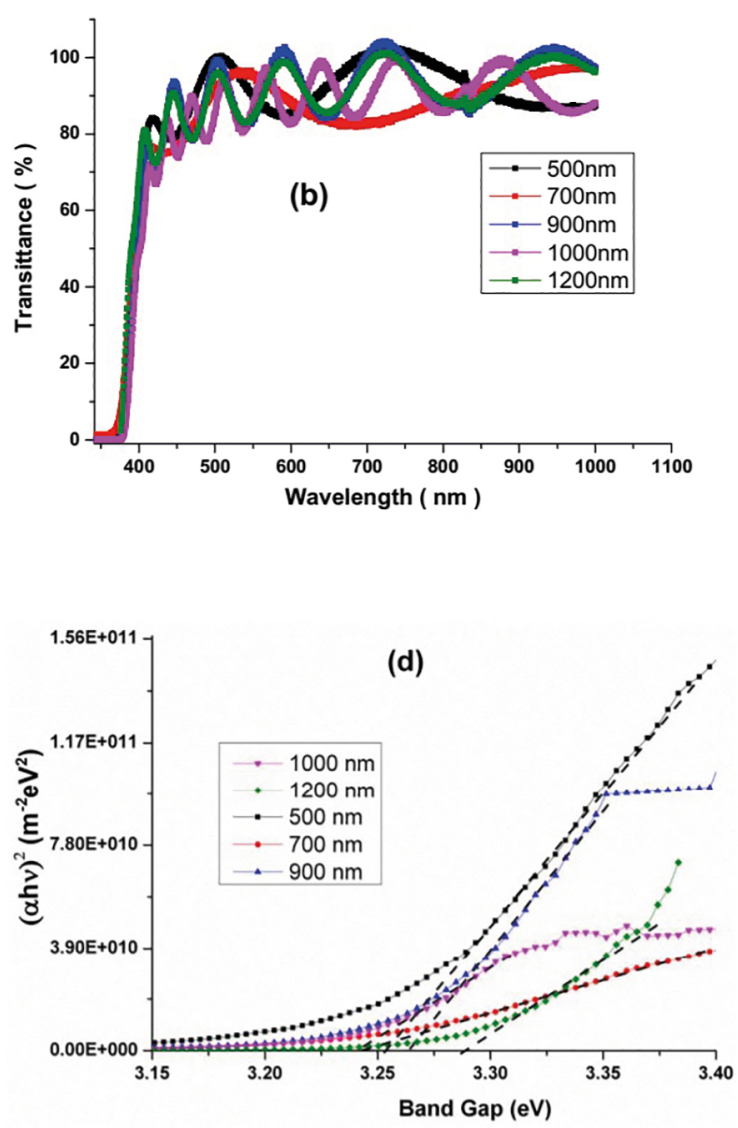

Figure 2. UV transmissions spectra for (a) thinner films (10 -200 nm) and (b) for higher thickness (500 -1200 nm), (c) and (d) are the corresponding band gap respectively.

Table 1. Optical band gap and refractive index at $550 \mathrm{~nm}$ for $\mathrm{ZnO}$ films on glass at different thickness.

\begin{tabular}{lccccccccc}
\hline Thickness & 30 & 50 & 100 & 200 & 500 & 700 & 900 & 1000 & 1200 \\
\hline Band gap & 3.13 & 3.13 & 3.23 & 3.24 & 3.25 & 3.24 & 3.26 & 3.24 & 3.29 \\
Refractive index $(550 \mathrm{~nm})$ & --- & --- & --- & --- & 2.0418 & --- & 2.0440 & 2.0425 & 2.0430 \\
\hline
\end{tabular}

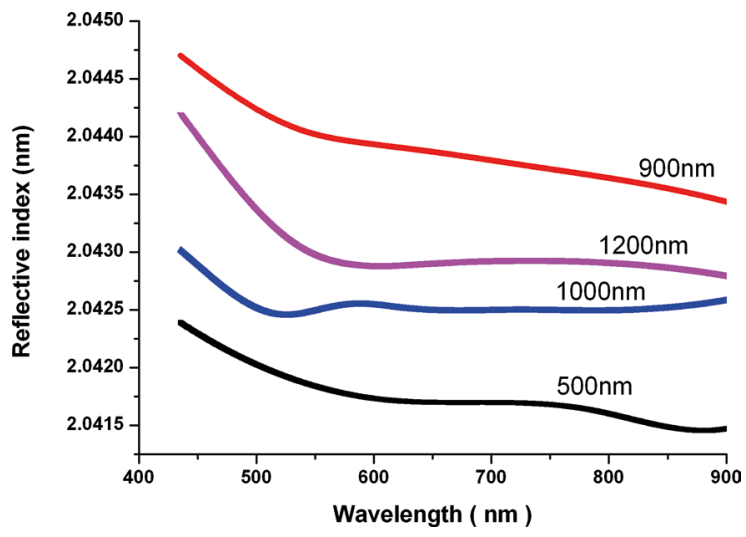

Figure 3. The evolution of the refractive index (n) as a function of wavelength for different film thicknesses raging from $(500-1200 \mathrm{~nm})$. 
becomes 1.91 by further annealing at $400{ }^{\circ} \mathrm{C} / 1 \mathrm{~h}$. In our result the refractive index at $633 \mathrm{~nm}$ was about 2.0425 at $1000 \mathrm{~nm}$ film. Additionally, an earlier study of the RF sputtered $\mathrm{ZnO}$ film (a thickness of $1000 \mathrm{~nm}$ ) by Mehan et al. ${ }^{29}$ revealed that the refractive index at $\lambda=550 \mathrm{~nm}$ was 1.980 but it was 2.006 for the $\mathrm{ZnO}$ bulk. The quality of sputtered $\mathrm{ZnO}$ films can influence refractive index. Our value at the same $\lambda$ and thickness was 2.0425 which is close to the bulk $\mathrm{ZnO}$ value (table (1)).

The increase of $\mathrm{n}$ with thickness can be ascribed to the increase in the grain size and the enhancement of the crystalline quality. We have seen during the crystallographic study that the grain size and the crystallinity were enhanced as the film thickness increased. The samples of lower thickness must contain much more defects like oxygen vacancies which constitute an important source of free carriers. As the grain size increases the amount of oxygen vacancies decreases to some extent leading, thus, to a decrease in the free carrier density ${ }^{30}$.

Our results show that the refractive index increases for 500, 1000 and $1200 \mathrm{~nm}$ films as shown in figure 3 (except for $900 \mathrm{~nm}$ ). This behavior comes in agreement with ref ${ }^{31}$. This could be explained by the improvement of the crystalline quality (grain size figure 1(b) and lower stress with thickness ${ }^{21}$.

\subsubsection{Photoluminesce study}

\subsubsection{PL at Room Temperature (RT)}

PL spectra include a peak for direct band gap emission at about $380 \mathrm{~nm}(3.25 \mathrm{eV})$ in the UV region, two peaks at about 420, $436 \mathrm{~nm}$ might be attributed to $\mathrm{Zn}$ vacancy and interstitial respectively (blue region) ${ }^{32}$, and a broad peak at about $550 \mathrm{~nm}$ which might be attributed to oxygen vacancies or interstitials (green region).
The intensity of band gap emission increases with thickness (figure 4(a)) correspondingly FWHM decreases (figure 4(b)) which indicate better quality i.e. The crystalline quality was found to improve, while the stress values decreased with increasing thickness ${ }^{21,23,33}$.

\subsubsection{PL at low temperature}

PL spectra reveal a blue emission band attributed to localized donor states (for single crystal and $1200 \mathrm{~nm}$ film). At low temperatures $(<80 \mathrm{~K})$ PL spectra are dominated by the emission attributed to the recombination of excitons bound to neutral donors (for SC) figure 5(a). At higher temperatures $(>100 \mathrm{~K})$, defect related emissions in the visible range become comparable with the excitonic emission (for SC). But for the $1200 \mathrm{~nm}$ film the PL spectra at LT the intensity of the free exciton emission $(370 \mathrm{~nm})$ and green emission $(\sim 550$ $\mathrm{nm})$ are comparable but at RT the green emission become dominate due to defects in the prepared films figure 5(b).

In the region between $380 \mathrm{~nm}$ and $450 \mathrm{~nm}$ (blue region), two weak emission bands at about $413(3.0 \mathrm{eV})$ and $436 \mathrm{~nm}(2.84$ $\mathrm{eV})$ appeared in the studied film but is not exist in the $\mathrm{SC}^{34}$.

Two broad band appear clearly in the region $(\sim 550 \mathrm{~nm})$ for $\mathrm{ZnO}$ studied film (figure 5(b)) are attributed to the deep level emissions. The band located at about $607 \mathrm{~nm}(2.04 \mathrm{eV})$, is known as yellow emission in $\mathrm{ZnO}$. Wu et al. ${ }^{35}$ proposed that the single negatively charged interstitial oxygen $(\mathrm{O}-\mathrm{i})$ is responsible for the yellow luminescence.

Also PL intensity and its FWHM at low temperature for $\mathrm{ZnO}$ single crystal and $1200 \mathrm{~nm}$ film showed similar behavior figure 5(c) and figure 5(d). The increasement of the PL intensity at low temperatures is due to increasing of exciton and defects bindings. This was accompanied with a decreasing of $\mathrm{FWHM}^{34}$. This supports that $\mathrm{ZnO}$ film is a good quality due to its sharp excitonic emission ${ }^{19}$.
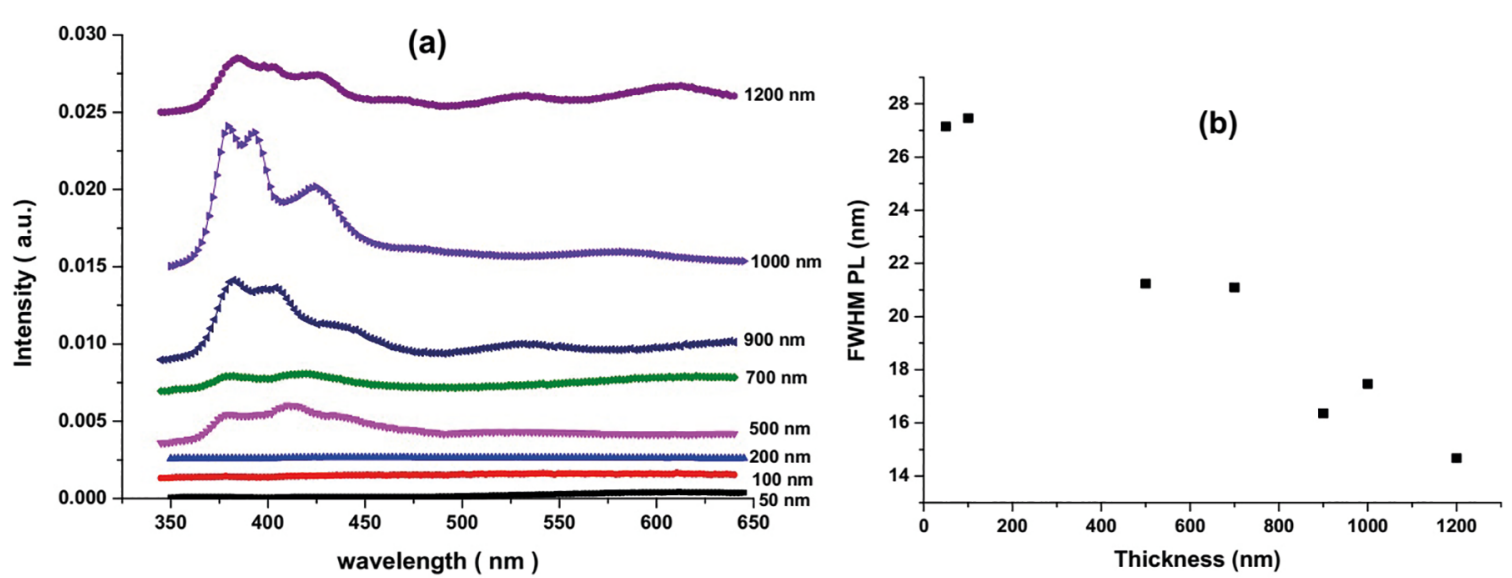

Figure 4. (a) PL spectra at RT, (b) FWHM for band gap emission as a function of $\mathrm{ZnO} / \mathrm{Si}$ film thickness. 

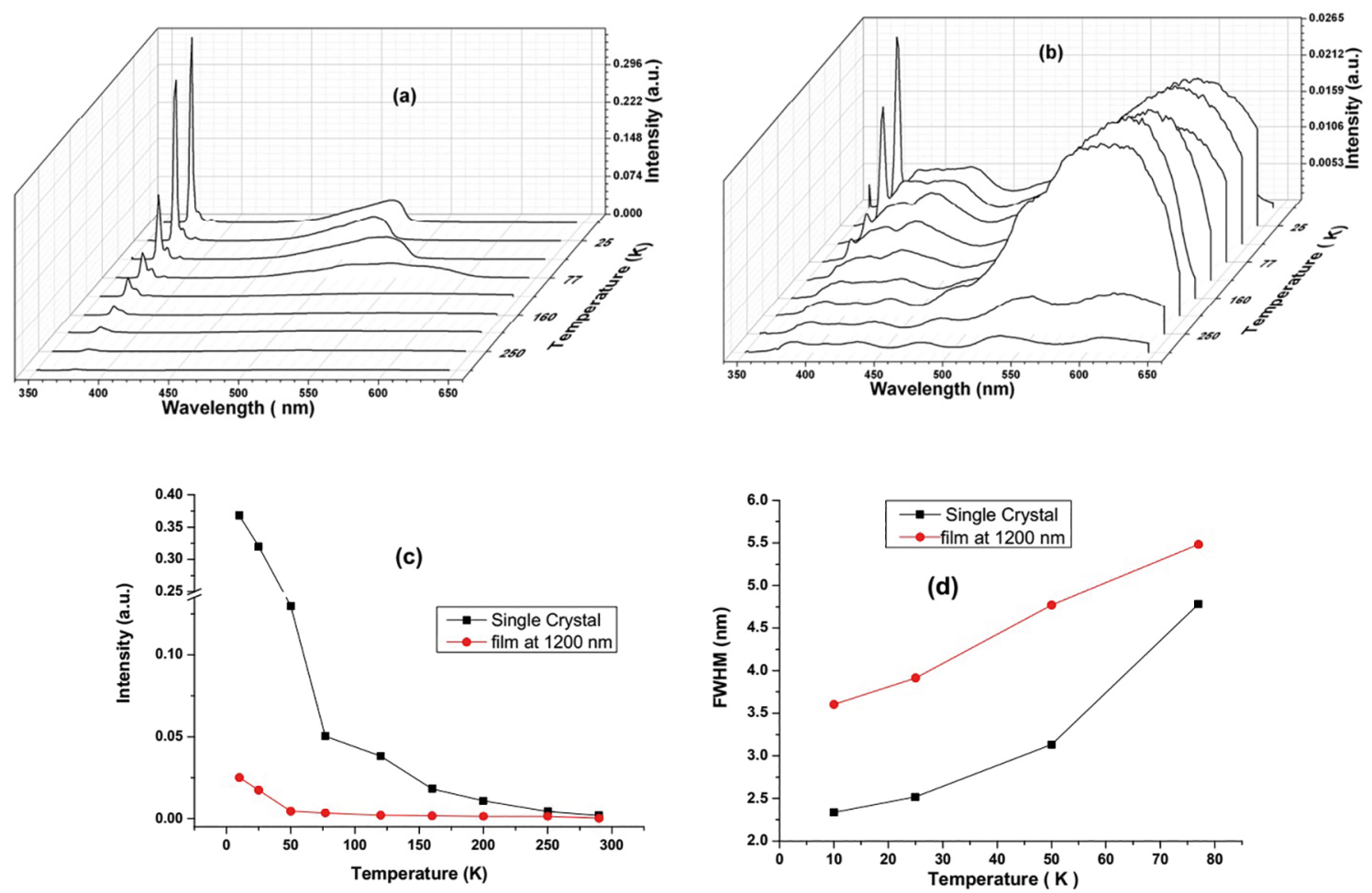

Figure 5. PL spectra at low temperature (a) for single crystal and (b) for ZnO film, (c) and (d) intensity and FWHM for band gap emission for $\mathrm{SC}$ and prepared film respectively.

\section{Conclusions}

High transparent $\mathrm{ZnO}$ films, using RF magnetron sputtering method, have been prepared with different thicknesses on silicon and glass substrates. The influence of thickness on the optical and structural properties has been studied where quality improvement (grain size from XRD) has compared with PL and UV measurements. FWHM of band gap PL emission decrease from $27 \mathrm{~nm}$ to $14 \mathrm{~nm}$ for films deposited on silicon substrate. Optical band gap and refractive indices values have been deduced from UV spectra for films deposited on glass. Also FWHM of PL at low temperature for $1000 \mathrm{~nm}$ film and $\mathrm{ZnO}$ single crystal showed similar behavior where it increases with temperature. The resistivity as a function of grain size was found to be changed from $0.2184 \Omega \mathrm{cm}$ to $2.975 \Omega \mathrm{cm}$ for studied films.

\section{Acknowledgement}

Authors would like to thank Prof. I. Othman, the Director General of AECS for encouragement and financial support and M. Alsabagh for PL measurements.

\section{References}

1. Wang ZA, Chu JB, Zhu HB, Sun Z, Chen YW, Huang SM. Growth of ZnO:Al films by RF sputtering at room temperature for solar cell applications. Solid-State Electronics. 2009;53(11):11491153.

2. Persson C. Thin-film $\mathrm{ZnO} / \mathrm{CdS} / \mathrm{CuIn}{ }_{1-\mathrm{x}} \mathrm{Ga}_{\mathrm{x}} \mathrm{Se}_{2}$ solar cells: anomalous physical properties of the $\mathrm{CuIn}{ }_{1-\mathrm{x}} \mathrm{Ga}_{\mathrm{x}} \mathrm{Se}_{2}$ absorber. Brazilian Journal of Physics. 2006;36(3b):948-951.

3. Oh BY, Jeong MC, Moon TH, Lee W, Myoung JM, Hwang JY, et al. Transparent conductive Al-doped $\mathrm{ZnO}$ films for liquid crystal displays. Journal of Applied Physics. 2006;99(12):124505.

4. Pearton SJ, Lim WT, Wright JS, Tien LC, Kim HS, Norton DP, et al. $\mathrm{ZnO}$ and Related Materials for Sensors and Light-Emitting Diodes. Journal of Electronic Materials. 2008;37(9):1426-1432.

5. Hoffman RL, Norris BJ, Wager JF. ZnO-based transparent thinfilm transistors. Applied Physics Letters. 2003;82(5):733-735.

6. Zhu J, Chen H, Saraf G, Duan Z, Lu Y, Hsu ST. ZnO TFT Devices Built on Glass Substrates. Journal of Electronic Materials. 2008;37(9):1237-1240.

7. Shinde VR, Gujar TP, Lokhande CD. Enhanced response of porous $\mathrm{ZnO}$ nanobeads towards LPG: Effect of Pd sensitization. Sensors and Actuators B: Chemical. 2007;123(2):701-706. 
8. Basu PK, Battacharyya P, Saha N, Saha H, Basu S. The superior performance of the electrochemically grown $\mathrm{ZnO}$ thin films as methane sensor. Sensors and Actuators B: Chemical. 2008;133(2):357-363.

9. Sahay PP, Nath RK. Al-doped $\mathrm{ZnO}$ thin films as methanol sensors. Sensors and Actuators B: Chemical. 2008;134(2):654659.

10. Bi Z, Zhang JW, Bian XM, Wang D, Zhang X, Zhang WF, et al. A High-Performance Ultraviolet Photoconductive Detector Based on a ZnO Film Grown by RF Sputtering. Journal of Electronic Materials. 2008;37(5):760-763.

11. Liu CH, Liu BC, Fu ZX. Electrical and deep levels characteristics of $\mathrm{ZnO} / \mathrm{Si}$ heterostructure by MOCVD deposition. Chinese Physics B. 2008;17(6):2292-2297.

12. Fu YQ, Garcia-Gancedo L, Pang HF, Porro S, Gu YW, Luo JK, et al. Microfluidics based on $\mathrm{ZnO} /$ nanocrystalline diamond surface acoustic wave devices. Biomicrofluidics. 2012;6(2):024105.

13. Shishiyanu ST, Shishiyanu TS, Lupan OI. Sensing characteristics of tin-doped $\mathrm{ZnO}$ thin films as $\mathrm{NO}_{2}$ gas sensor. Sensors and Actuators B: Chemical. 2005;107(1):379-386.

14. Rahmane S, Djouadi MA, Aida MS, Barreau N, Abdallah B, Hadj Zoubir N. Power and pressure effects upon magnetron sputtered aluminum doped $\mathrm{ZnO}$ films properties. Thin Solid Films. 2010;519(1):5-10.

15. Silva EP, Chaves M, Durrant SF, Lisboa-Filho PN, Bortoleto JRR. Morphological and electrical evolution of $\mathrm{ZnO}$ : Al thin films deposited by RF magnetron sputtering onto glass substrates. Materials Research. 2014;17(6):1384-1390.

16. Zahedi F, Dariani RS, Rozati SM. Spray Pyrolysis Deposition of $\mathrm{ZnO}$ Thin Films from Zinc Chloride Precursor Solution at Different Substrate Temperatures. Acta Metaurgica Sinica (English Letters). 2015;28(1):110-114. DOI: 10.1007/s40195014-0177-5

17. Rahmane S, Abdallah B, Soussou A, Gautron E, Jouan PY, Le Brizoual L, et al. Epitaxial growth of $\mathrm{ZnO}$ thin films on AlN substrates deposited at low temperature by magnetron sputtering. Physica Status Solidi A. 2010;207(7):1604-1608.

18. Suvorova NA, Usov IO, Stan L, DePaula RF, Dattelbaum AM, Jia QX, et al. Structural and optical properties of $\mathrm{ZnO}$ thin films by rf magnetron sputtering with rapid thermal annealing. Applied Physics Letters. 2008;92(14):141911.

19. Park WI, Jun YH, Jung SW, Yi GC. Excitonic emissions observed in $\mathrm{ZnO}$ single crystal nanorods. Applied Physics Letters. 2003;82(6):964-966.

20. Abdallah B, Al-Khawaj S. Optical and Electrical Characterization of (002)-Preferentially Oriented n-ZnO/p-Si Heterostructure. Acta Physica Polonica A. 2015;128(3):283-288.

21. Al-Khawaja S, Abdallah B, Abou Shaker S, Kakhia M. Thickness effect on stress, structural, electrical and sensing properties of $(0$ 02 ) preferentially oriented undoped $\mathrm{ZnO}$ thin films. Composite Interfaces. 2015;22(3):221-231.
22. van der Pauw LJ. A method of measuring specific resistivity and hall effect of discs of arbitrary shape. Philips Research Reports. 1958;13:1-9.

23. Myoung JM, Yoon WH, Lee DH, Yun I, Bae SH, Lee SY. Effects of Thickness Variation on Properties of $\mathrm{ZnO}$ Thin Films Grown by Pulsed Laser Deposition. Japanese Journal of Applied Physics. 2002;41(Pt 1):28.

24. David T, Goldsmith S, Boxman RL. Dependence of zinc oxide thin film properties on filtered vacuum arc deposition parameters. Journal of Physics D: Applied Physics. 2005;38(14):2407.

25. Manifacier JC, Gasiot J, Fillard JP. A simple method for the determination of the optical constants $\mathrm{n}, \mathrm{k}$ and the thickness of a weakly absorbing thin film. Journal of Physics E: Scientific Instruments. 1976;9(11):1002.

26. Singh BP, Singh V, Tyagi RC, Sharma TP. Effect of ambient hydrogen sulfide on the physical properties of vacuum evaporated thin films of zinc sulfide. Applied Surface Science. 2008;254(8):2233-2237.

27. Khelladi NB, Chabane Sari NE. Simulation Study of Optical Transmission Properties of $\mathrm{ZnO}$ Thin Film Deposited on Different Substrates. American Journal of Optics and Photonics. 2013;1(1):1-5.

28. Moustaghfir A, Tomasella E, Ben Amor S, Jacquet M, Cellier J, Sauvaget T. Structural and optical studies of $\mathrm{ZnO}$ thin films deposited by r.f. magnetron sputtering: influence of annealing. Surface and Coatings Technology. 2003;174-175:193-196.

29. Mehan N, Gupta V, Sreenivas K, Mansingh A. Effect of annealing on refractive indices of radio-frequency magnetron sputtered waveguiding zinc oxide films on glass. Journal of Applied Physics. 2004;96(6):3134-3139.

30. Bouderbala M, Hamzaoui S, Amrani B, Reshak Ali H, Adnane M, Sahraoui T, et al. Thickness dependence of structural, electrical and optical behaviour of undoped $\mathrm{ZnO}$ thin films. Physica B: Condensed Matter. 2008;403(18):3326-3330.

31. Ting CC. Structure, Morphology, and Optical Properties of the Compact, Vertically-Aligned ZnO Nanorod Thin Films by the Solution-Growth Technique. In: Yalçin O, ed. Nanorods. Rijeka: InTech; 2012. p. 33-50.

32. Wu KY, Fang QQ, Wang WN, Zhou C, Huang WJ, Li JG, et al. Influence of nitrogen on the defects and magnetism of $\mathrm{ZnO}: \mathrm{N}$ thim films. Journal of Applied Physics. 2010;108(6):063530.

33. Ryu YR, Zhu S, Budai JD, Chandrasekhar HR, Miceli PF, White HW. Optical and structural properties of $\mathrm{ZnO}$ films deposited on GaAs by pulsed laser deposition. Journal of Applied Physics. 2000;88(1):201-204.

34. Morales AE, Aceves R, Pal U, Zhang JZ. Low Temperature Photoluminescence Characteristics of Chemically Synthesized Indium Doped Zinc Oxide Nanostructures. Journal of Nanoscience and Nanotechnology. 2008;8(12):6538-6544.

35. Wu XL, Siu GG, Fu CL, Ong HC. Photoluminescence and cathodoluminescence studies of stoichiometric and oxygen-deficient ZnO films. Applied Physic Letters. 2001;78(16):2285-2287. 